\title{
DEVELOPMENT OF STATIC ARMOUR
}

\author{
Cahyono Ikhsan ${ }^{1)}$ \\ ${ }^{1)}$ Civil Engineering Departement, Sebelas Maret Universitas, Solo, Central Java, Indonesia \\ e-mail: cahyono1970@yahoo.co.id
}

\begin{abstract}
Armour layer is the type of gravel bed composed on the bed surface with pores between the composing grains as the place of sand to stay and lock the pores. This research was carried out in the Hydraulic Laboratory by using the main infrastructure of sediment flume from Plexiglas in $0.60 \mathrm{~m}$ width, $10.00 \mathrm{~m}$ length, and $0.45 \mathrm{~m}$ height dimension. The base gradients used was parallel to the water surface gradients, which were $1 \%, 1.4 \%, 1.8 \%, 2.2 \%$, and $2.6 \%$. The constant flow debit was at $25 \mathrm{l} / \mathrm{s}, 30 \mathrm{l} / \mathrm{s}, 40 \mathrm{l} / \mathrm{s}$ and $45 \mathrm{l} / \mathrm{s}$ capacity. The materials consisted of sand and gravel and were evenly mixed in 5 different grain size variations. At each running, there were 2 phases of occurrence: eroded surface and equilibrium. The instruments used during the running were digital current meter, point gauge, and sediment traps. The results of this research indicated armour layer formula stated in un-dimensional number with an average bedload limit of $0.8 \mathrm{~mm}$ to $2.9 \mathrm{~mm}$, uniformity coefficient of 2.5 to 5 , and critical shear stress of $0.61 \mathrm{~N} / \mathrm{m}^{2}$ to $2.7 \mathrm{~N} / \mathrm{m}^{2}$ and with minimum base shear stress of $6 \mathrm{~N} / \mathrm{m}^{2}$.
\end{abstract}

Keywords: shear stress, base gradient, armour layer, grain size, flume

\begin{abstract}
ABSTRAK
Armour layer merupakan jenis gravel bed yang tersusun di atas permukaan dasar, memiliki rongga-rongga antar butir penyusunnya, sebagai tempat berlindung butir pasir untuk tinggal dan mengunci rongga tersebut.Penelitian dilakukan di laboratorium Hidraulika, menggunakan perangkat utama sediment recirculacy flume pada dinding terbuat dari plexiglass dengan dimensi panjang $10,00 \mathrm{~m}$, lebar $0,60 \mathrm{~m}$, tinggi $0,45 \mathrm{~m}$. Kemiringan dasar saluran yaitu $1 \%$, $1.4 \%, 1,8 \%, 2,2 \%$, dan 2,6\%. Debit aliran konstan pada kapasitas 25 1/s, 30 1/s, 40 1/s dan 45 1/s. Material berupa pasir dan gravel dicampur merata, dengan 5 variasi grain size yang berbeda. Pada tiap running terdapat 2 fase kejadian yaitu fase eroded surface dan fase equilibrium. Instrumen yang digunakan pada saat running adalah digital currentmeter, point gauge, sediment traps. Hasil penelitian ini dapat dirumuskan tentang tebal armour layer yang dinyatakan dalam bilangan tak berdimensi dengan nilai rata-rata diameter bedload antara $0,8 \mathrm{~mm}$ sampai dengan 2,9 mm; koefisien uniformity 2,5 sampai dengan 5; tegangan geser kritik 0,61 N/m² sampai dengan $2,7 \mathrm{~N} / \mathrm{m}^{2}$; tegangan geser dasar minimal $6 \mathrm{~N} / \mathrm{m}^{2}$.
\end{abstract}

Kata kunci : shear stress, kemiringan dasar, armour layer, grainsize, flume

\section{PENDAHULUAN}

Material sedimen yang terkandung di dasar sungai memiliki ukuran butir yang bervariasi membentuk sistem lapisan sedimen yang dapat dikelompokkan menjadi tiga komponen yang berbeda (Gambar 1). Komponen pertama adalah bedload layer, merupakan sedimen yang senantiasa bergerak di atas permukaan dasar dengan melompat, menggelinding dan bergeser. Lapisan tersebut memiliki diameter rata-rata paling kecil dan merupaka jenis golongan pasir. Komponen kedua adalah armour layer, merupakan sedimen dasar yang berada di lapisan permukaan (surface layer), memiliki diameter rata-rata ukuran butir (grain size) paling besar dan hampir seragam. Lapisan tersebut merupaka jenis gravel berfungsi sebagai pelindung (armour) terhadap lapisan di bawahnya. 


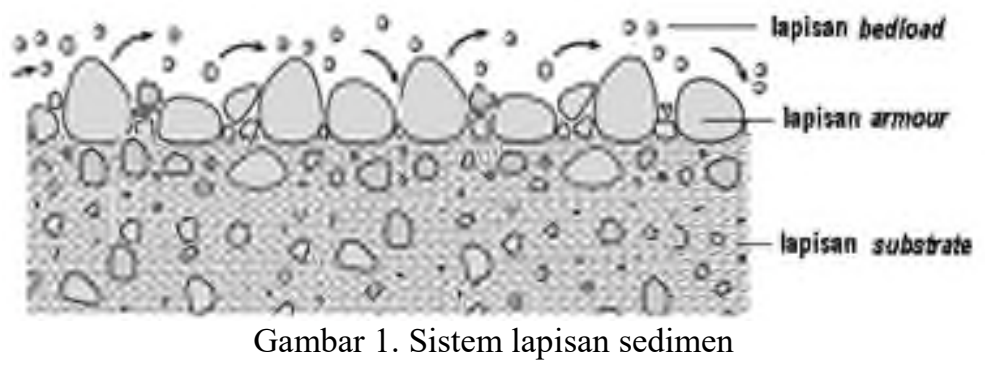

Komponen ketiga adalah substrate layer, merupakan sedimen dasar yang berada di bawah armour layer, terdiri dari campuran antara pasir dan gravel, dengan jumlah pasir lebih dominan.

Proffitt (1980) menyebutkan bahwa armour layer melindungi lapisan di bawahnya (substrate), Parker et.al (1982) membahas karakteristik ukuran butir pada lapisan substrate dengan menganalisa besarnya sedimen yang terangkut pada satu ukuran butir (a single grain size), Shen dan Lu (1983) mengembangkan suatu metoda untuk memprediksi distribusi lapisan armour. Parker (1990) mengembangkan persamaan lapisan armour pada tiap fraksi butir dan diameter rata-rata lapisan. Wilcock (2001) menyebutkan bahwa pembentukan lapisan armour didasarkan pada perbedaan tegangan geser yang terjadi pada fraksi pasir dan gravel. Wilcock (2003) mengembangkan suatu hubungan antara bedload dengan lapisan armour serta substrate yang tergambar pada distribusi grain size secara keseluruhan, termasuk adanya butir pasir yang mengisi gravel pada saat terjadi angkutan sedimen. Curran dan Wilcock (2005) melakukan eksperimen flume dengan intensitas debit yang besar dan mengukur bedload yang terangkut dan tertinggal di dasar. Sistem sedimen di dasar sungai terdiri dari tiga lapisan komponen pembentuk, ketiga lapisan tersebut adalah lapisan surface, substrate dan bedload. Parker (1990a), Wilcock (2001), Wilcock and Crowe (2003) membahas tentang karakteristik ukuran butir pada lapisan permukaan (surface grain size characteristics). Persamaan yang dikemukakan oleh Parker-Klingeman-McLean (1982) tentang ukuran butir pada lapisan dasar permukaan (substrate grain sizes). Metode yang dikemukakan oleh Bakke (1999) adalah pada kedua lapisan (surface and substrate) tergantung pada prosentase campuran gravel dan pasir. Metode gabungan yaitu metode Wilcock (2001) dan Bakke (1982), pengukuran sedimen dasar yang hasilnya dapat dipakai untuk kalibrasi persamaan angkutan sedimen. Curran dan Tan (2010) meneliti tentang formasi klaster armouring. Struktur lapisan armour yang terbentuk merupakan campuran gravel dan pasir yang tersortir secara periodik.

\section{RUMUS STATIC ARMOUR}

Armouring adalah suatu proses terbentuknya lapisan pelindung permukaan yang diawali oleh pergerakan butiran dasar yang terangkut secara kontinu akibat dari tegangan geser dasar lebih besar dari tegangan geser kritis butirannya, mengakibatkan terjadinya erosi permukaan sampai pada kondisi lapisan dasar permukaan stabil yaitu tidak ada lagi butiran dasar yang terangkut, dan yang tertinggal di dasar permukaan merupakan jenis gravel dan pasir, namun didominasi gravel yang memiliki ukuran butiran hampir seragam.

Lapisan pelindung tersebut tidak bergerak, memiliki rongga-rongga antar butir penyusunnya. Rongga pada struktur lapisan pelindung tersebut sebagai tempat pertukaran antar butir lapisan dasar yang mengakibatkan butiran saling mengunci dan saling menguatkan, sehingga struktur lapisan pelindung semakin kokoh di dasar permukaan, melindungi butiran yang lebih kecil di bawahnya dan memiliki ukuran diameter butir pembentuk lapisan pelindung dengan ketebalan tertentu.

Dari uraian tersebut, maka parameter penyusun tebal lapisan pelindung adalah: diameter butir lapisan pelindung (Da), massa jenis air $(\rho)$, selisih tegangan geser $(\Delta \tau)$, keseragaman ukuran butiran $(\mathrm{Cu})$ dan kecepatan aliran $(\mathrm{U})$. Parameter tersebut dinyatakan secara matematis dalam fungsi tebal lapisan pelindung yaitu:

$$
L_{a}=f\left(C_{u}, D_{b 50}, \Delta \tau, \tau_{c b}\right)
$$

Atau

$$
\phi\left[\frac{L_{a}}{D_{b 50}}, C_{u}, \frac{\Delta \tau}{\tau_{c b}}\right]=0
$$

maka persamaan bilangan non dimensional

$$
f\left(\frac{D_{a}}{D_{b}}, \frac{(\Delta \tau)}{\tau}, C_{u}\right)=0
$$


Selanjutnya melakukan analisis dimensi dengan memakai Metode Basic Stepwise. Adapun satuan SI pada parameter fungsi tersebut adalah: massa jenis air (ML-3), diameter butiran lapisan pelindung (L), keseragaman ukuran butiran (L/L), kecepatan aliran (LT-1) dan selisih tegangan geser (ML-1T-2).

Selanjutnya, secara bertahap, satuan pada fungsi tersebut dibagi dengan M pada parameter $\rho$ (ML-3), T pada parameter U(LT-1) dan L pada parameter $\mathrm{Da}(\mathrm{L})$, yang dijelaskan pada analisis bilangan tak berdimensi sebagai berikut:

\begin{tabular}{ccccc}
\hline$\rho$ & $D_{a}$ & $C_{u}$ & $U$ & $\Delta \tau$ \\
$\left(\mathrm{ML}^{-3}\right)$ & $(\mathrm{L})$ & $\frac{(\mathrm{L})}{(\mathrm{L})}$ & $\left(\mathrm{LT}^{-1}\right)$ & $\left(\mathrm{ML}^{-1} \mathrm{~T}^{-2}\right)$ \\
\hline
\end{tabular}

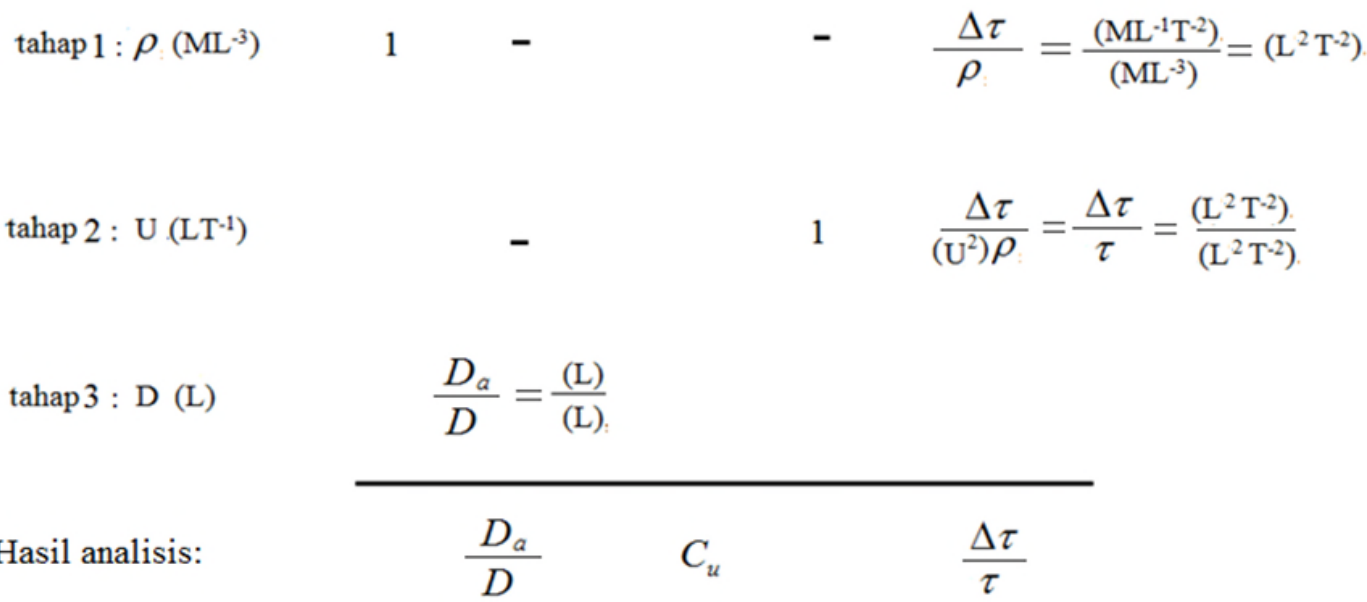

Selanjutnya disusun dalam fungsi bilangan tak berdimensi yaitu:

$$
f\left(\frac{D_{a}}{D_{b}}, \frac{(\Delta \tau)}{\tau}, C_{u}\right)=0
$$

Atau

$$
f\left(\frac{D_{a 50}}{D_{b 50}}, \frac{\left(\tau_{0}-\tau_{c}\right)}{\tau_{c}}, C_{u}\right)=0
$$

atau

$$
\frac{D_{a 50}}{D_{b 50}}=f\left(\frac{\left(\tau_{o}-\tau_{c}\right)}{\tau_{c}}, C_{u}\right)
$$

Pada persamaan tersebut terdiri tiga kompoen bilangan tak berdimensi yang saling berpengaruh pada mekanisme armouring yaitu $\frac{D_{a 50}}{D_{b 50}}$ sebagai pembentuk tebal lapisan pelindung, $\tau_{c}$ merupakan selisih tegangan geser dasar permukaan dan ${ } \quad D_{a 16}$ merupakan keseragaman butiran.

$$
C_{u}=\frac{D_{a 90}}{D_{a 16}} \text { merupakan keseragaman butiran. }
$$

Pada komponen tegangan geser dasar, komponen tersebut harus senantiasa bernilai positif, maka pada persamaan dilakukan modifikasi dengan suatu nilai $\theta$ agar diperoleh grafik tegangan geser bernilai positif, sedangkan untuk keseragaman ukuran butiran, dilakukan modifikasi dengan suatu nilai $\lambda$ agar diperoleh nilai keseragaman butiran minimal satu, maka persamaan tersebut berubah menjadi:

$$
\frac{D_{a 50}}{D_{b 50}}=\left(\frac{\tau_{o}-\tau_{c}}{\tau_{c}}-\theta\right)\left(C_{u}-\lambda\right)
$$


Selanjutnya persamaan tersebut dilakukan perkalian $\alpha_{\text {dan pangkat }} \beta$ pada tegangan geser, sedangkan untuk keseragaman ukuran butiran dipangkat $\gamma$, maka persamaan tersebut menjadi:

$$
\frac{D_{a 50}}{D_{b 50}}=\alpha\left(\frac{\tau_{o}-\tau_{c}}{\tau_{c}}-\theta\right)^{\beta}\left(C_{u}-\lambda\right)^{\gamma}
$$

Atau

$$
\frac{L_{a}}{D_{b 50}}=\alpha\left[\frac{\tau_{o}-\tau_{c b}}{\tau_{c b}}-\theta\right]^{\beta}\left[C_{u}-\lambda\right]^{\gamma}
$$

\section{KONDISI EKSPERIMEN}

Penelitian dilakukan dengan menggunakan a small, tilting, sediment feed flume dengan dimensi panjang 10,0 m, tinggi 0,45 m, dan lebar flume 0,6 m. Jenis aliran steady uniform pada kondisi low flow debit konstan $251 / \mathrm{s}, 30$ 1/s, 40 1/s dan 45 1/s untuk setiap running dengan variasi kemiringan dasar (So) 1\%, 1,4\%, 1,8\%, 2,2\%, 2,6\% untuk setiap jenis variasi material (M1, M2, M3, M4, M5).

Eksperimen sedimen dasar (bedload) terdiri dari fraksi butir dengan ukuran gradasi butir bervariasi, dan terdiri 5 material yang berbeda. Setiap material pada saat running ditunjukkan pada Tabel berikut :

Tabel 1. Setting awal eksperimen

\begin{tabular}{ccccccc}
\hline \multirow{2}{*}{$(\mathbf{I} / \mathbf{S})$} & \multirow{2}{*}{ So } & $\begin{array}{c}\mathbf{1 \%} \\
\mathbf{h}(\mathbf{m})\end{array}$ & $\begin{array}{c}\mathbf{1 . 4 0 \%} \\
\mathbf{h}(\mathbf{m})\end{array}$ & $\begin{array}{c}\mathbf{1 . 8 0} \% \\
\mathbf{h}(\mathbf{m})\end{array}$ & $\begin{array}{c}\mathbf{2 . 2 0} \% \\
\mathbf{h}(\mathbf{m})\end{array}$ & $\begin{array}{c}\mathbf{2 . 6 0 \%} \\
\mathbf{h}(\mathbf{m})\end{array}$ \\
\hline $\mathbf{2 5}$ & & 0.080 & 0.071 & 0.066 & 0.061 & 0.058 \\
$\mathbf{3 0}$ & & 0.090 & 0.080 & 0.074 & 0.069 & 0.065 \\
$\mathbf{4 0}$ & 0.108 & 0.090 & 0.089 & 0.083 & 0.079 \\
$\mathbf{4 5}$ & 0.117 & 0.104 & 0.096 & 0.090 & 0.085 \\
\hline
\end{tabular}

Material sedimen eksperimen di pisah dengan ukuran diameter butir yang berbeda dan masing-masing dicat dengan warna berbeda. Ukuran diameter butir tersebut yaitu D30, D50, D80 dan D95. Adapun warna yang dipakai adalah kuning, hijau, merah dan putih disesuakan dengan ukuran diameter butirnya.

Nilai tegangan geser kritik setiap fraksi butir diambil dari kurva tegangan geser Shields. Besarnya tegangan geser yang terdapat pada butir sedimen dasar memberikan batasan tentang kondisi sedimen (terangkut atau diam). Bila fraksi butir terangkut, maka fraksi butir tersebut memiliki nilai tegangan geser lebih besar dari tegangan geser kritisnya, demikian juga sebaliknya maka faksi butir tersebut tetap diam (static). Pada tabel 2 disajikan tegangan geser dasar pada tiap running.

\begin{tabular}{|c|c|c|c|c|}
\hline Sf & $\begin{array}{c}\tau\left(\mathrm{N} / \mathrm{m}^{2}\right) \\
\mathrm{Q}=25 \mathrm{l} / \mathrm{s}\end{array}$ & $\begin{array}{c}\tau\left(\mathrm{N} / \mathrm{m}^{2}\right) \\
\mathrm{Q}=30 \mathrm{l} / \mathrm{s}\end{array}$ & $\begin{array}{c}\tau\left(\mathrm{N} / \mathrm{m}^{2}\right) \\
\mathrm{Q}=40 \mathrm{l} / \mathrm{s}\end{array}$ & $\begin{array}{c}\tau\left(\mathrm{N} / \mathrm{m}^{2}\right) \\
\mathrm{Q}=45 \mathrm{l} / \mathrm{s}\end{array}$ \\
\hline 0.01 & 7.85 & 8.63 & 10.01 & 10.79 \\
\hline 0.014 & 9.89 & 10.99 & 12.91 & 13.73 \\
\hline 0.018 & 12.01 & 13.07 & 15.36 & 16.42 \\
\hline 0.022 & 13.81 & 15.11 & 17.70 & 18.99 \\
\hline 0.026 & 15.56 & 17.34 & 20.00 & 21.43 \\
\hline
\end{tabular}

Tabel 2 Tegangan geser dasar

Pada eksperimen ini, mula-mula sedimen dicampur dan dimasukkan merata sepanjang flume dengan ketebalan $15 \mathrm{~cm}$, kemudian kemiringan dasar flume diatur sesuai dengan rencana. Selanjutnya menghidupkan pompa dan mengatur debit aliran sesuai rencana dengan jenis aliran steady uniform.

\section{RUNNING EKSPERIMEN}

Kaca flume terbuat terbuat dari plexiglass yang jelas dan bersih, yang memungkinkan pengamatan langsung terhadap angkutan sedimen Gambar 2. Pada sistem sirkulasi air flume, dilakukan feeding sedimen dari arah hulu dan pada bagian hilir di beri kotak saringan sebagai tangkapan sedimen (sediment trap). Tahapan running pada pelaksanaan penelitian, terdiri dari dua fasa yaitu degradasi dan equilibrium. 


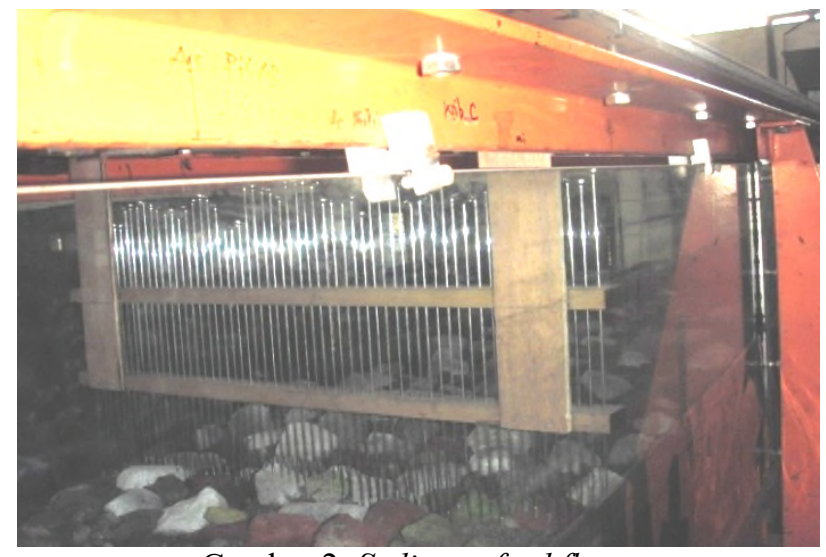

Gambar 2. Sediment feed flume

Fase degradasi ditandai dengan pengangkutan sedimen secara besar-besaran sampai dicapai pengangkutan maksimal, selanjutnya akan berkurang sampai diperoleh keseimbangan dinamis (equilibrium) yaitu ketika jumlah sedimen inflow (feeding) di hulu pada selang waktu tertentu menyamai jumlah sedimen outflow yang tertangkap oleh sediment trap di hilir flum.

Terbentuknya armour layer diawali dari kondisi equilibrium yang ditandai dengan semakin berkurang jumlah sedimen yang terangkut sampai mendekati nol.

\section{HASIL PENELITIAN}

Hasil pengamatan dan pengukuran yang dilakukan pada tiap running material pada variasi debit dan kemiringan dasar disajikan pada Tabel berikut :

Tabel 3. Hasil analisis eksperimen material 1

\begin{tabular}{|c|c|c|c|c|c|c|c|c|c|c|c|c|c|}
\hline Run & $\begin{array}{c}\mathrm{Q} \\
(1 / \mathrm{s})\end{array}$ & $\mathrm{S}$ & $\begin{array}{c}\mathrm{V} \\
(\mathrm{m} / \mathrm{s})\end{array}$ & $\begin{array}{c}\mathrm{h} \\
(\mathrm{mm})\end{array}$ & Fr & $\begin{array}{c}\tau \mathrm{O} \\
(\mathrm{N} / \mathrm{m} 2)\end{array}$ & $\begin{array}{l}\mathrm{Da} 90 \\
(\mathrm{~mm})\end{array}$ & $\begin{array}{l}\mathrm{Da} 15 \\
(\mathrm{~mm})\end{array}$ & $\mathrm{Cu}$ & $\begin{array}{l}\text { Da50 } \\
(\mathrm{mm})\end{array}$ & $\begin{array}{l}\mathrm{Db50} \\
(\mathrm{mm})\end{array}$ & $\begin{array}{c}(\tau \mathrm{O}-\tau \mathrm{c}) / \tau \mathrm{c} \\
(\mathrm{N} / \mathrm{m} 2)\end{array}$ & $\mathrm{La} / \mathrm{Db} 50$ \\
\hline M1Q1S1 & 25 & 0,010 & 0,53 & 80 & 0,60 & 7,85 & 86 & 35 & 2,46 & 42 & 2,00 & 1,91 & 21,00 \\
\hline M1Q1S2 & 25 & 0,014 & 0,59 & 71 & 0,70 & 9,75 & 86 & 35 & 2,46 & 45 & 2,00 & 2,61 & 22,50 \\
\hline M1Q1S3 & 25 & 0,018 & 0,64 & 66 & 0,79 & 11,65 & 89 & 36 & 2,47 & 48 & 2,00 & 3,32 & 24,00 \\
\hline M1Q1S4 & 25 & 0,022 & 0,68 & 61 & 0,88 & 13,17 & 90 & 35 & 2,57 & 50 & 2,00 & 3,88 & 25,00 \\
\hline M1Q1S5 & 25 & 0,026 & 0,72 & 58 & 0,95 & 14,79 & 91 & 34 & 2,68 & 52 & 2,00 & 4,48 & 26,00 \\
\hline M1Q2S1 & 30 & 0,010 & 0,56 & 90 & 0,60 & 8,83 & 86 & 35 & 2,46 & 40 & 2,40 & 2,27 & 16,72 \\
\hline M1Q2S2 & 30 & 0,014 & 0,63 & 80 & 0,71 & 10,99 & 88 & 35 & 2,51 & 44 & 2,40 & 3,07 & 18,17 \\
\hline M1Q2S3 & 30 & 0,018 & 0,68 & 74 & 0,80 & 13,07 & 89 & 35 & 2,54 & 47 & 2,40 & 3,84 & 19,41 \\
\hline M1Q2S4 & 30 & 0,022 & 0,72 & 69 & 0,88 & 14,89 & 90 & 34 & 2,65 & 54 & 2,40 & 4,52 & 22,52 \\
\hline M1Q2S5 & 30 & 0,026 & 0,76 & 65 & 0,95 & 16,58 & 92 & 33 & 2,79 & 58 & 2,40 & 5,14 & 24,21 \\
\hline M1Q3S1 & 40 & 0,010 & 0,62 & 108 & 0,60 & 10,59 & 86 & 35 & 2,46 & 62 & 3,50 & 2,92 & 17,69 \\
\hline M1Q3S2 & 40 & 0,014 & 0,69 & 96 & 0,71 & 13,18 & 89 & 34 & 2,62 & 67 & 3,50 & 3,88 & 19,10 \\
\hline M1Q3S3 & 40 & 0,018 & 0,75 & 89 & 0,80 & 15,72 & 90 & 32 & 2,81 & 79 & 3,50 & 4,82 & 22,55 \\
\hline M1Q3S4 & 40 & 0,022 & 0,80 & 83 & 0,89 & 17,91 & 91 & 31 & 2,94 & 82 & 3,50 & 5,63 & 23,43 \\
\hline M1Q3S5 & 40 & 0,026 & 0,85 & 79 & 0,96 & 20,15 & 93 & 31 & 3,00 & 89 & 3,50 & 6,46 & 25,43 \\
\hline M1Q4S1 & 45 & 0,010 & 0,64 & 117 & 0,60 & 11,48 & 87 & 34 & 2,56 & 66 & 3,70 & 3,25 & 17,76 \\
\hline M1Q4S2 & 45 & 0,014 & 0,72 & 104 & 0,71 & 14,28 & 89 & 33 & 2,70 & 75 & 3,70 & 4,29 & 20,31 \\
\hline M1Q4S3 & 45 & 0,018 & 0,78 & 96 & 0,80 & 16,95 & 90 & 32 & 2,81 & 81 & 3,70 & 5,28 & 21,89 \\
\hline M1Q4S4 & 45 & 0,022 & 0,83 & 90 & 0,89 & 19,42 & 93 & 30 & 3,10 & 83 & 3,70 & 6,19 & 22,43 \\
\hline M1Q4S5 & 45 & 0,026 & 0,88 & 85 & 0,96 & 21,68 & 93 & 28 & 3,32 & 84 & 3,70 & 7,03 & 22,70 \\
\hline
\end{tabular}

\section{PEMBAHASAN}

Variabel-variabel pada penelitan ini adalah diameter butir armour rata-rata $\left(D_{a 50}\right)$, tegangan geser $(\tau)$, tegangan geser kritis $\left(\tau_{c}\right)$, sedimen dasar (bedload), armour layer, uniformity coefficient $\left(\mathrm{C}_{\mathrm{u}}\right)$. Variabel tersebut merupakan hasil simulasi dari variasi Material (M1, M2, M3, M4, M5), debit aliran (Q1,Q2, Q3, Q4) dan kemiringan dasar saluran $\left(\mathrm{S}_{\mathrm{o}}\right)$ adalah $1.0 \%, 1.4 \%, 1,8 \%, 2,2 \%$ dan 2,6\% yang dapat dinyatakan secara matematis sebagai fungsi tebal armour: 


$$
L_{a}=f\left(C_{u}, D_{b 50}, \Delta \tau, \tau_{c b}\right)
$$

Pada penelitian ini terdapat 100 fungsi atau 100 data yang dimasukkan ke dalam lembar kerja excel dengan sistem koordinat $x-y$ yang merupakan hubungan antara $\left[\frac{\tau_{o}-\tau_{b c}}{\tau_{b c}}-1,22\right]$ dengan $\frac{L_{a}}{D_{b 50}}$, disajikan pada gambar 3

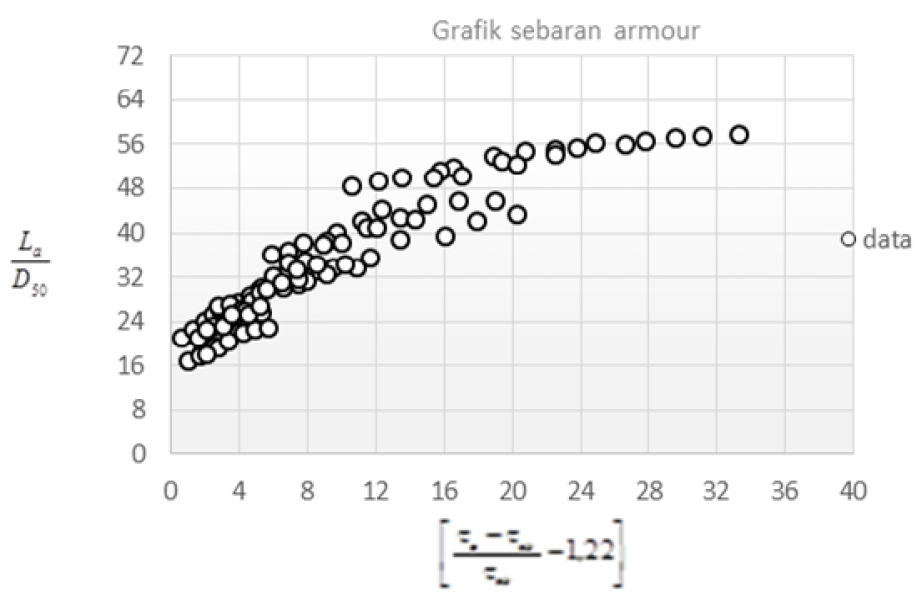

Gambar 3. Sebaran 100 data Armour layer

Mencari nilai $\alpha, \beta, \gamma$ dengan metode kuadrat terkecil (least square method). Dengan cara yang sama untuk setiap running, dari running 1 sampai dengan running 100, selanjutnya dilakukan analisa optimasi dengan memakai Excel Solver pada 100 fungsi.

Dari analisis tersebut diperoleh nilai optimal disetiap sel, dengan nilai koefisien optimasi $\alpha, \beta, \gamma$ adalah :

$$
\begin{aligned}
& \alpha=13,59 \\
& \beta=0,41 \\
& \gamma=0,10
\end{aligned}
$$

Dengan adanya nilai optimasi $\alpha, \beta, \gamma$ tersebut, maka persamaan armour layer menjadi :

$$
\frac{L_{a}}{D_{b 50}}=13,59\left[\frac{\tau_{o}-\tau_{c b}}{\tau_{c b}}-1,22\right]^{0,41}\left[C_{u}-1,50\right]^{0,10}
$$

Pada persamaan tersebut dibuat kurve yang mewakili kondisi sebaran semua data hasil running tersebut : 


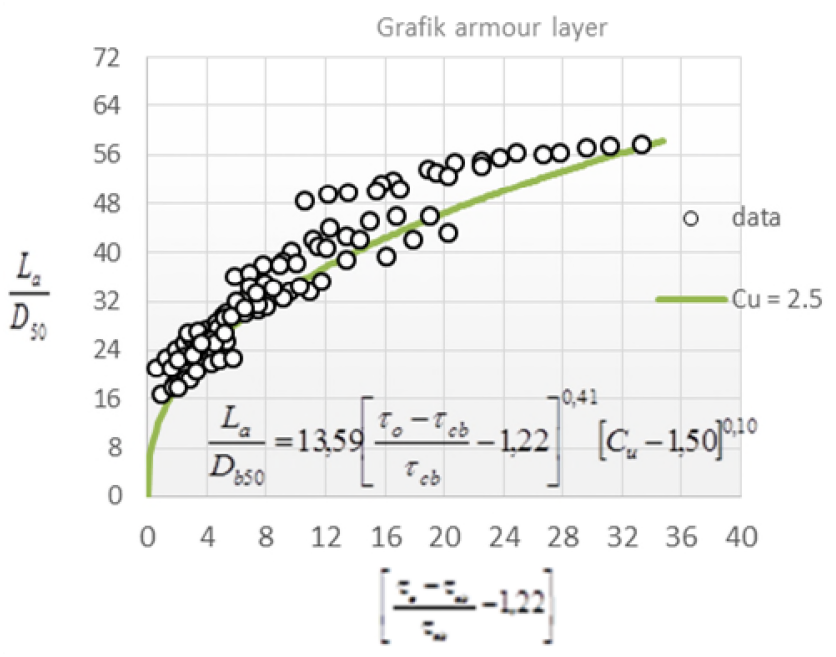

ambar 4. Kurva armour layer dengan $\mathrm{Cu}=2,5$ pada sebaran 100 data

\section{KESIMPULAN}

Dari uraian di atas, yang mengacu pada kajian pustaka, teori, analisis awal, hasil eksperimen dan pembahasan maka kami menarik kesimpulan sebagai berikut;

1. Struktur penyusun armour layer didominasi oleh gravel bad dengan jumlah mencapai $80 \%$, dengan posisi butir yang menonjol di permukaan dasar. Diameter butir penyusun armour layer relative lebih besar dari lapisan di bawahnya (substrate layer), namun pada struktur penyusun armour layer masih terdapat pasir yang berlindung di antara rongga armour.

2. Pembentukan armour layer terjadi bila jumlah bedload yang terangkut sudah mencapai maksimal. Butir bedload akan terangkut bila tegangan geser dasar melebihi tegangan geser kritis butir tersebut, dalam hal ini tagangan geser kritis butir $\left(\tau_{c b}\right)$ antara $0.61 \mathrm{~N} / \mathrm{m}^{2}$ sampai dengan $2.70 \mathrm{~N} / \mathrm{m}^{2}$ dengan diameter butir rata-rata antara $0.8 \mathrm{~mm}$ sampai dengan $2.9 \mathrm{~mm}$.

3. Terbentuknya static armour merupakan proses perubahan profil distribusi grainsize dasar yang terjadi akibat pengaruh uniformity butiran, pada proses eroded surface bedload sebagai efek adanya tegangan geser lebih besar dari tegangan geser kritis butir, sampai dengan bedload yang terangkut semakin berkurang mendekati nol, sehingga butiran yang tertinggal di flume merupakan butir armour yang memiliki rumus ketebalan:

$$
\frac{L_{a}}{D_{b 50}}=13.59\left[\frac{\tau_{o}-\tau_{c b}}{\tau_{c b}}-1.22\right]^{0.41}\left[C_{u}-1.5\right]^{0.10}
$$

\section{DAFTAR PUSTAKA}

Crowe, J.C. and Lu Tan, 2010, An Investigation of Bed Armoring Process And The Formation of Microclusters. Joint Federal Interagency Conference, Las Vegas.

Proffitt, G. T. (1980).Selective transport and armouring of non-uniform alluvial sediments, Res. Rept. 80-22, Dept. Civil Eng., University of Canterbury, NZ, 203pp.

Proffitt, G. T. (1980). Selective transport and armouring of non-uniform alluvial sediments, Res. Rept. 80-22, Dept. Civil Eng., University of Canterbury, NZ, 203pp.

Parker, G., and Klingeman, P.C., 1982, On why gravel bed streams are paved, Water Resources Research, 18(5), 1409-1423.

Parker, G., Klingeman, P.C., and McLean, D.L., 1982, Bedload and size distribution in paved gravel bed streams, Journal of Hydraulics Division, ASCE, v. 108, p. 544-571.

Parker, G., 1990a, Surface-based bedload transport relation for gravel rivers, Journal of Hydraulic Research, v. 28, p. 417-436.

Sutherland, A.J. (1987)Static armour layers by selective ero $\neg$ sion. Sediment Transport in Gravel-Bed Rivers, C.R. Thorne et al., Wiley, Chichester, 243-60.

Shen, H. W. and LU, J-Y (1983). Development and prediction of bed armouring, Proc. Am. Soc. Civ. Engrs, J. 
Hydraul. Eng., 109(HY4), 611-629.

US Army Corps of Engineering, 1995, Engineering and Design Sedimentation Investigation of River and Resevoirs. EM 1110-2-4000. Department of Army.,Washington, D.C. 20314

Wilcock, P.R., 2001, Toward a practical method for estimating sediment-transport rates in gravel-bed rivers, Earth Surface Processes and Landforms, v. 26, p. 1395-1408.

Wilcock, P.R. and J.C. Crowe, 2003, Surface-based transport model for mixed size sediment, Journal of Hydraulic Engineering, v. 129, p. 120-128.

Wilcock, P.R. and J.C. Crowe, 2005, Effect of sand Supply on transport rates in a gravel bed channel. Journal of Hydraulic Engineering, v. 131, no.11 : 961-967. 